\title{
Improving Electronic Survey Response Rates Among Cancer Center Patients During the COVID-19 Pandemic: Mixed Methods Pilot Study
}

Cassandra A Hathaway ${ }^{1}$, BS, MPH; Melody N Chavez ${ }^{2}$, MPH; Mika Kadono ${ }^{3}$, MPH, PhD; Dana Ketcher ${ }^{4}$, MPH, $\mathrm{PhD}$; Dana E Rollison ${ }^{1}$, PhD; Erin M Siegel ${ }^{1}$, MPH, PhD; Anita R Peoples ${ }^{5,6}, \mathrm{MPH}, \mathrm{PhD}$; Cornelia M Ulrich ${ }^{5,6}$, PhD; Frank J Penedo ${ }^{7}, \mathrm{PhD}$; Shelley S Tworoger ${ }^{1,8^{*}}, \mathrm{PhD}$; Brian D Gonzalez ${ }^{4^{*}}, \mathrm{PhD}$

\footnotetext{
${ }^{1}$ Department of Cancer Epidemiology, Moffitt Cancer Center, Tampa, FL, United States

${ }^{2}$ Participant Research, Interventions, and Measurements Core, Moffitt Cancer Center, Tampa, FL, United States

${ }^{3}$ The AltaMed Institute for Health Equity, Los Angeles, CA, United States

${ }^{4}$ Department of Health Outcomes and Behavior, Moffitt Cancer Center, Tampa, FL, United States

${ }^{5}$ Huntsman Cancer Institute, Salt Lake City, UT, United States

${ }^{6}$ Department of Population Health Sciences, University of Utah, Salt Lake City, UT, United States

${ }^{7}$ Departments of Medicine and Psychology, University of Miami, Coral Gables, FL, United States

${ }^{8}$ Department of Epidemiology, Harvard T.H. Chan School of Public Health, Boston, MA, United States

*these authors contributed equally
}

\section{Corresponding Author:}

Shelley S Tworoger, PhD

Department of Cancer Epidemiology

Moffitt Cancer Center

13131 USF Magnolia Drive

MRC 2nd Floor

Tampa, FL, 33612

United States

Phone: 18137451810

Email: Shelley.Tworoger@moffitt.org

\section{Abstract}

Background: Surveys play a vital role in cancer research. During the COVID-19 pandemic, the use of electronic surveys is crucial to improve understanding of the patient experience. However, response rates to electronic surveys are often lower compared with those of paper surveys.

Objective: The aim of this study was to determine the best approach to improve response rates for an electronic survey administered to patients at a cancer center during the COVID-19 pandemic.

Methods: We contacted 2750 patients seen at Moffitt Cancer Center in the prior 5 years via email to complete a survey regarding their experience during the COVID-19 pandemic, with patients randomly assigned to a series of variations of prenotifications (ie, postcard, letter) or incentives (ie, small gift, modest gift card). In total, eight combinations were evaluated. Qualitative interviews were conducted to understand the level of patient understanding and burden with the survey, and quantitative analysis was used to evaluate the response rates between conditions.

Results: A total of $262(9.5 \%)$ patients completed the survey and 9 participated in a qualitative interview. Interviews revealed minimal barriers in understanding or burden, which resulted in minor survey design changes. Compared to sending an email only, sending a postcard or letter prior to the email improved response rates from $3.7 \%$ to $9.8 \%$. Similarly, inclusion of an incentive significantly increased the response rate from $5.4 \%$ to $16.7 \%$, especially among racial (3.0\% to $12.2 \%)$ and ethnic (6.4\% to $21.0 \%)$ minorities, as well as among patients with low socioeconomic status (3.1\% to $14.9 \%)$.

Conclusions: Strategies to promote effective response rates include prenotification postcards or letters as well as monetary incentives. This work can inform future survey development to increase response rates for electronic surveys, particularly among hard-to-reach populations. 
(JMIR Cancer 2021;7(3):e30265) doi: 10.2196/30265

\section{KEYWORDS}

response rates; electronic survey; cancer; COVID-19; pandemic; surveillance; cancer patients; health promotion; digital health; patient experience; health outcomes

\section{Introduction}

Surveys are a critical aspect of many research studies, and electronic surveys are increasingly being used in research. Benefits of electronic compared to paper surveys include greater reach, higher survey completeness, lower costs, flexibility in survey design, real-time data access, and increased willingness of participants to share information [1-4]. Prior work has demonstrated that the vast majority of research participants, including cancer patients, prefer a computer-assisted survey compared to a paper-based survey $[2,5,6]$.

Nevertheless, compared with mailed or in-person paper surveys, electronic surveys tend to have lower response rates and decreasing response rates over time [7-10], although most studies using paper surveys also experience attrition with follow-up [11-15]. Response rates, regardless of survey type, are usually lower in minority racial and ethnic groups, as well as among those with poorer health status, lower incomes, and lower education [16]. A study among breast cancer patients found that those who were older, had lower education levels, and had worse quality of life were more likely to prefer paper-based surveys to collect health data, indicating a potential barrier to electronic surveys in these populations [17].

As a consequence of the COVID-19 pandemic, there is reduced face-to-face interaction with research participants, increasing the need to reach study participants using remote approaches $[18,19]$. Thus, it is critical to evaluate potential approaches to engage participants and enhance the response to electronic surveys. For example, shortening the length of the survey and improving the clarity of questions can reduce the burden and improve understanding, leading to higher response rates [10,20-23]. Additionally, monetary and nonmonetary incentives, a notification prior to administering the survey, including an image in the email, and follow-up contact may also enhance participation $[4,10,21,22]$. To address the growing need to enhance response rates for electronic surveys, we used a mixed methods approach to (1) assess participant burden and understanding through qualitative interviews, and (2) quantitatively evaluate the impact of prenotifications and incentives on response rates of an electronic survey during the COVID-19 pandemic among individuals who were seen at a cancer center.

\section{Methods}

\section{Study Population}

This study included patients at Moffitt Cancer Center who were seen between January 1, 2015 and September 13, 2020; had English as a preferred language; were between 40 and 89 years old; lived in the cancer center catchment area; had a valid email address; and a last known vital status of alive. Half of the patients in this study had previously consented to an institutional biobanking study (Total Cancer Care: MCC14690, Advarra IRB Pro00014441; Moffitt Cancer Center Screening and Prevention Study: MCC14453, USF IRB 103792). We randomly selected patients for each pilot condition with oversampling of Hispanic and Black/African American patients. Similar to the general Moffitt Cancer Center population, the participants included in this study were those diagnosed with invasive and in situ cancer, benign diseases, and patients who were screened without a cancer diagnosis. The survey contained questions regarding COVID-19-specific behaviors, testing, symptoms and treatment, demographics, medical history, health behaviors, and psychosocial well-being (143 total items across 26 web pages). Participants were able to change their answers through a "back" button if desired. The survey was tested with staff members before sending to participants to check for usability, technical functionality, and appropriate wording. After surveys were submitted, they were reviewed by study staff for completeness.

\section{Ethical Statement}

This study was approved by Advarra Inc (MCC 20629, Pro00043372). Emails invited eligible patients to the study and included a unique link to an information and consent page. This page included a description of the study goals, the approximate length of the survey, a Health Insurance Portability and Accountability Act authorization if they were not consented to a biobanking study or information about the biobanking study they had consented to previously, and the Institutional Review Board contact information. At the bottom of this web page was a unique link, based on the patient's email address, to start the voluntary survey.

\section{Pilot Conditions}

We evaluated eight different conditions with an email sent with a survey link for each condition, and various methods of prenotifications and incentives were tested based on findings from prior literature [10,20-23]. Although prior studies have shown that prenotifications and incentives improve response rates, there has been little work performed in this regard with cancer center patients, especially during the pandemic; therefore, we considered multiple methods and their combinations. Participants in the first condition $(\mathrm{n}=1000)$ received a lengthy (380-528 words) text-only email discussing the aim of the study, study procedures, and links for more information about the COVID-19 pandemic and the cancer center's response. Due to cost and time constraints, the subsequent conditions included 250 patients each. Participants in conditions 2-8 received a condensed version of the email sent in condition 1, containing only a few sentences (119-142 words), with the cancer center's logo and an image of the principal investigators' signatures. Participants in condition 2 received only the condensed email, those in condition 3 received a mailed letter from the principal investigators of the study and the center's Associate Center 
Director of Clinical Science, which discussed the importance of the work and noted that an email with the survey link would be sent shortly; this was followed by a condensed email 3 to 4 days after mailing the letter. Condition 4 was the same as condition 3 but with the addition of a small gift (Moffitt-branded adhesive phone wallet) in the envelope. Participants in condition 5 received a postcard about the study and asked patients to look for an email with a survey link, which was sent 3 to 4 days later. Participants in condition 6 received only the condensed email with an additional note stating that an electronic US \$10 gift card would be sent via email within 5 days of completion of the survey. Participants in condition 7 received the same letter as sent in condition 3 , further noting a US $\$ 10$ gift card incentive upon survey completion. Participants in the final condition received a postcard noting that an email will be sent with a US $\$ 10$ gift card after completing the survey. For all conditions, up to two reminder emails were sent in 4-day intervals.

\section{Covariates}

We collected information on current age (continuous), years since their most recent visit to the cancer center $(<2$ years, $2-5$ years), gender (male, female), race (White, non-White), ethnicity (non-Hispanic, Hispanic), cancer status (invasive cancer, benign, in situ, or no cancer diagnosis), and zip code to assess the area deprivation index (ADI) decile rank for the state of Florida, which ranges from 1 to 10 . The ADI ranks neighborhoods based on socioeconomic factors, including income, education, employment, and housing quality, with a higher ADI rank indicating a greater socioeconomic disadvantage [24,25]. All variables were obtained through medical records and Cancer Registry data; missing information was supplemented with self-reported data from the survey where possible (eg, self-reported race and ethnicity). Data collected on the survey were linked to medical record data. All data were stored on a secured, password-protected server.

\section{Qualitative Interviews}

Individual qualitative interviews were conducted with survey participants to better understand their motivations to participate in the survey, and to assess understanding of the survey questions and participant burden. Upon completion of the survey, participants within condition 1 (long email only) were asked if they would like to volunteer for an interview to provide feedback about their survey experience. A research coordinator contacted participants who volunteered and obtained verbal consent via telephone. Videoconference interviews $(n=9)$ were scheduled an average of 4 weeks after participants completed the survey and were conducted by two trained interviewers (MC and MK). A semistructured interview guide was used with two primary domains: understanding and burden, informed by health literacy models and the perceived research burden literature [26-28]. The interviews were conducted over a period of 2 weeks using Zoom [29,30]. The interviews lasted an average of 21 minutes and were audio-recorded with participant consent. Data saturation was reached after nine interviews with participants in the first condition; therefore, we did not conduct interviews with the other pilot conditions.

\section{Qualitative Data Analysis}

Interview transcripts were analyzed using rapid ethnographic methods [31,32] and constant comparison analysis [33], an integrative process of cumulative and concurrent data generation and analysis, to identify emergent themes that informed continuing data collection [34]. These methods were adopted to accommodate the time-sensitive nature of the research, since the survey was ongoing during analysis. Emergent themes were identified and agreed upon by the researchers, and when available, specific quotes that were representative of each theme were selected and segmented. Data saturation was reached after nine interviews (ie, no new themes emerged), consistent with other qualitative studies [35,36].

\section{Statistical Analysis}

We calculated response rates for each pilot condition and compared groups of conditions (eg, pre-email notification vs none, incentive vs none) by calculating overall response rates as well as response rates within key sociodemographic groups. We used $\chi^{2}$ tests to assess statistical differences in response rates and logistic regression was used to estimate the odds of completing the survey between groups of conditions. We also used logistic regression analysis to assess the odds of response for each condition (compared to condition 2 with only the condensed email) adjusting for sociodemographic factors that were found to be significantly associated with response rates in univariable logistic regression. All $P$ values were two-sided and analytic results were considered statistically significant if $P<.05$. Study data were collected and managed using REDCap electronic data capture tools hosted at Moffitt Cancer Center $[37,38]$. Analyses were performed using SAS version 9.4 (SAS Institute Inc).

\section{Results}

\section{Population Characteristics}

Among the 2750 patients contacted, a total of 262 patients (9.5\%) completed the survey. Compared to the total invited population, those who completed the survey were slightly older, more likely to be female, less likely to be Black, and more likely to be Hispanic (Table 1). Those with higher measures of socioeconomic status (ie, a lower ADI rank) were also more likely to complete the survey (mean decile rank of 4.5 vs 5.0 among the invited population). Most patients had a cancer diagnosis $(75 \%)$, approximately $7 \%$ of those contacted had a benign or in situ diagnosis, and $18 \%$ had no reported cancer diagnosis. The survey took an average of 18.4 minutes to complete. Demographic information for each pilot condition is shown in Multimedia Appendix 1. 
Table 1. Demographic characteristics of participants who completed the survey and those who were invited to participate.

\begin{tabular}{|c|c|c|}
\hline Characteristics & Completed survey $(n=262)$ & Invited to survey $(\mathrm{n}=2750)$ \\
\hline Time to complete survey (minutes), mean (SD) & $18.4(14.3)$ & $\mathrm{N} / \mathrm{A}^{\mathrm{a}}$ \\
\hline Age (years), mean (SD) & $65.6(10.9)$ & $64.5(11.6)$ \\
\hline Years since last Moffitt visit, mean (SD) & $1.0(1.3)$ & $1.5(1.6)$ \\
\hline Area Deprivation Index State Decile Rank, mean $(\mathrm{SD})^{\mathrm{b}}$ & $4.5(2.6)$ & $5.0(2.7)$ \\
\hline \multicolumn{3}{|l|}{ Gender, n (\%) } \\
\hline Male & $118(45.0)$ & $1339(48.7)$ \\
\hline Female & $144(55.0)$ & $1411(51.3)$ \\
\hline \multicolumn{3}{|l|}{ Race, $\mathbf{n}(\%)$} \\
\hline American Indian & $0(0)$ & $4(0.2)$ \\
\hline Asian/Pacific Islander & $1(0.4)$ & $41(1.5)$ \\
\hline Black & $26(9.9)$ & $379(13.8)$ \\
\hline Other & $4(1.5)$ & $69(2.5)$ \\
\hline White & $231(88.2)$ & $2192(79.7)$ \\
\hline Unknown & $0(0)$ & $65(2.4)$ \\
\hline \multicolumn{3}{|l|}{ Ethnicity, n (\%) } \\
\hline Hispanic & $38(14.5)$ & $378(13.8)$ \\
\hline Non-Hispanic & $224(85.5)$ & $2312(84.1)$ \\
\hline Unknown & $0(0)$ & $60(2.2)$ \\
\hline \multicolumn{3}{|l|}{ Cancer status, $\mathbf{n}(\%)$} \\
\hline Invasive & $212(80.9)$ & $2058(74.8)$ \\
\hline Benign or in situ & $9(3.4)$ & $193(7.0)$ \\
\hline No cancer & $41(15.7)$ & $499(18.2)$ \\
\hline \multicolumn{3}{|l|}{ Stage at first diagnosis ${ }^{\mathrm{c}}, \mathrm{n}(\%)$} \\
\hline 0 & $9(4.3)$ & $77(3.7)$ \\
\hline 1 & $64(30.2)$ & $476(23.1)$ \\
\hline 2 & $28(13.2)$ & $280(13.6)$ \\
\hline 3 & $16(7.6)$ & $183(8.9)$ \\
\hline 4 & $17(8.0)$ & $157(7.6)$ \\
\hline Unknown & $78(36.8)$ & $885(43.0)$ \\
\hline \multicolumn{3}{|l|}{ Recruitment method, n (\%) } \\
\hline Long email only & $26(9.9)$ & $1000(36.4)$ \\
\hline Condensed email only & $20(7.6)$ & $250(9.1)$ \\
\hline Condensed email + letter & $28(10.7)$ & $250(9.1)$ \\
\hline Condensed email + letter + gift $^{\mathrm{d}}$ & $39(14.9)$ & $250(9.1)$ \\
\hline Condensed email + postcard & $21(8.0)$ & $250(9.1)$ \\
\hline Condensed email + gift card & $36(13.7)$ & $250(9.1)$ \\
\hline Condensed email + letter + gift card & $46(17.6)$ & $250(9.1)$ \\
\hline Condensed email + postcard + gift card & $46(17.6)$ & $250(9.1)$ \\
\hline
\end{tabular}

${ }^{\mathrm{a}} \mathrm{N} / \mathrm{A}$ : not applicable.

${ }^{b}$ Missing: $n=11$ completed survey, $n=100$ invited to survey.

${ }^{\mathrm{b}}$ Among those diagnosed with invasive or metastatic cancer. 
${ }^{\mathrm{c}}$ The gift included a Moffitt-branded adhesive phone wallet inside the envelope.

\section{Qualitative Interviews}

The qualitative interview responses were summarized using a priori determined themes (ie, understanding, burden) and emergent themes (ie, access, question-specific feedback). All participants reported being able to understand and comprehend most survey questions; however, participants also reported that if they did not understand the question, they skipped it. If participants were unable to answer the question accurately with the answers provided, they answered the best they could. When available, participants clarified their answers in a free-text field at the end of the survey and suggested adding free-text fields to some questions to allow participants to clarify their responses, which were then added to the survey for subsequent conditions.

Participants did not report experiencing stress due to the survey; however, some participants commented that the survey was too long. One participant who was not undergoing treatment said, "If I wasn't feeling well, I'll tell you this [survey] is the last thing I'd do." Other participants mentioned the extra effort required to answer questions about their cancer history, such as recalling specific dates, diagnosis (ie, first, recurrence), treatments, and medications. Other burden-related comments included high levels of stress participants were experiencing in their lives (ie, due to cancer, COVID-19 pandemic) and feeling isolated. Given this initial feedback, several questions were removed or reworded in the survey to reduce participant burden.

Participants did not report difficulty accessing the survey, although interviewed participants were among those who successfully completed the survey and agreed to provide feedback. They felt that the email was clear and the links were easy to find. However, participants did provide specific suggestions related to improving access, including the use of text messages or the patient portal to notify participants that a survey was emailed. Most participants did not have feedback or recommendations to improve access to the survey.

\section{Condition Response Rates}

Table 2 presents response rates for the overall sample and sociodemographic subgroups. The pilot condition with the lowest response rate was the long email only and the highest responses were for the conditions with a prenotification (either letter or postcard) and receiving a US $\$ 10$ gift card for completing the survey. Further, differences in response rates were observed for the pilot conditions based on sociodemographic factors. For example, those receiving an email, postcard, and gift card had the highest response rates among non-White individuals and those with lower socioeconomic status, and participants of Hispanic ethnicity responded more frequently when receiving an email, letter, and gift card. Women had a higher response when a letter and an incentive were included, showing similar results if the incentive was a gift or a gift card. Alternatively, men responded more frequently when there was a postcard and a gift card, although responses were only slightly lower for the letter-only or the letter+gift card conditions.

Multivariable logistic regression was used to evaluate the odds of survey completion by pilot condition and sociodemographic factors. Compared with receiving only the condensed email, adding a letter and gift, a gift card, a letter and gift card, or a postcard and gift card significantly increased the odds of survey response (Table 3). Further, having previously consented to a Moffitt biobanking study versus not was related to a higher odds of survey response. Having a worse socioeconomic disadvantage (ADI rank 6-10 vs 1-5) as well as the last visit to the cancer center being more than 2 years from the date of the email led to a decreased response. Results were similar in the univariable models (data not shown). 
Table 2. Response rates for each condition overall and by sociodemographic factor.

\begin{tabular}{|c|c|c|c|c|c|c|c|c|}
\hline Sociodemographic factor & $\begin{array}{l}\text { Long email } \\
\text { only } \\
(n=1000)\end{array}$ & $\begin{array}{l}\text { Email only } \\
(\mathrm{n}=250)\end{array}$ & $\begin{array}{l}\text { Email+letter } \\
(\mathrm{n}=250)\end{array}$ & $\begin{array}{l}\text { Email+let- } \\
\text { ter+gift } \\
(\mathrm{n}=250)\end{array}$ & $\begin{array}{l}\text { Email+post- } \\
\text { card }(\mathrm{n}=250)\end{array}$ & $\begin{array}{l}\text { Email+gift } \\
\text { card }(n=250)\end{array}$ & $\begin{array}{l}\text { Email+let- } \\
\text { ter+ gift card } \\
(\mathrm{n}=250)\end{array}$ & $\begin{array}{l}\text { Email+post- } \\
\text { card+gift } \\
\text { card }(n=250)\end{array}$ \\
\hline $\begin{array}{l}\text { Minutes to complete survey, } \\
\text { mean (SD) }\end{array}$ & $20.4(21.1)$ & $14.6(9.6)$ & $15.6(7.0)$ & $18.3(11.5)$ & $21.7(22.0)$ & $22.0(18.6)$ & $16.6(7.1)$ & $18.4(14.3)$ \\
\hline Overall response rate & $2.6 \%$ & $8.0 \%$ & $11.2 \%$ & $15.6 \%$ & $8.4 \%$ & $14.4 \%$ & $18.4 \%$ & $18.4 \%$ \\
\hline \multicolumn{9}{|l|}{ Race } \\
\hline White & $3.1 \%$ & $9.0 \%$ & $11.7 \%$ & $18.1 \%$ & $8.9 \%$ & $15.9 \%$ & $19.0 \%$ & $18.7 \%$ \\
\hline Non-White & $0.0 \%$ & $2.6 \%$ & $9.1 \%$ & $4.3 \%$ & $6.4 \%$ & $8.2 \%$ & $16.0 \%$ & $17.3 \%$ \\
\hline \multicolumn{9}{|l|}{ Ethnicity } \\
\hline Non-Hispanic & $2.8 \%$ & $8.1 \%$ & $11.3 \%$ & $16.8 \%$ & $7.9 \%$ & $15.6 \%$ & $16.9 \%$ & $17.0 \%$ \\
\hline Hispanic & $1.5 \%$ & $7.4 \%$ & $10.3 \%$ & $8.3 \%$ & $11.8 \%$ & $7.9 \%$ & $27.0 \%$ & $25.0 \%$ \\
\hline \multicolumn{9}{|l|}{ Gender } \\
\hline Male & $1.7 \%$ & $8.8 \%$ & $15.2 \%$ & $11.8 \%$ & $5.8 \%$ & $12.2 \%$ & $15.4 \%$ & $18.1 \%$ \\
\hline Female & $3.3 \%$ & $7.4 \%$ & $7.2 \%$ & $20.2 \%$ & $10.8 \%$ & $16.8 \%$ & $21.9 \%$ & $18.7 \%$ \\
\hline \multicolumn{9}{|l|}{ Years since last visit } \\
\hline$<2$ & $3.3 \%$ & $8.1 \%$ & $14.9 \%$ & $17.3 \%$ & $9.9 \%$ & $17.4 \%$ & $21.1 \%$ & $20.4 \%$ \\
\hline $2-5$ & $1.0 \%$ & $6.9 \%$ & $3.4 \%$ & $12.2 \%$ & $5.1 \%$ & $7.7 \%$ & $12.0 \%$ & $13.0 \%$ \\
\hline \multicolumn{9}{|l|}{ Age (years) } \\
\hline$<65$ & $2.8 \%$ & $4.1 \%$ & $10.8 \%$ & $11.2 \%$ & $5.6 \%$ & $14.2 \%$ & $21.1 \%$ & $19.2 \%$ \\
\hline$\geq 65$ & $2.5 \%$ & $11.7 \%$ & $11.5 \%$ & $18.9 \%$ & $10.6 \%$ & $14.6 \%$ & $15.7 \%$ & $17.7 \%$ \\
\hline \multicolumn{9}{|l|}{ Cancer status } \\
\hline Invasive cancer & $3.0 \%$ & $7.6 \%$ & $14.0 \%$ & $16.8 \%$ & $9.8 \%$ & $14.4 \%$ & $17.8 \%$ & $20.5 \%$ \\
\hline $\begin{array}{l}\text { Benign, in situ, or no } \\
\text { cancer }\end{array}$ & $1.2 \%$ & $9.1 \%$ & $5.1 \%$ & $12.1 \%$ & $4.5 \%$ & $14.5 \%$ & $20.8 \%$ & $10.9 \%$ \\
\hline \multicolumn{9}{|l|}{$\mathrm{ADI}^{\mathrm{a}}$ decile } \\
\hline 1-5 (less disadvantaged) & $2.9 \%$ & $9.9 \%$ & $13.8 \%$ & $17.2 \%$ & $12.0 \%$ & $14.9 \%$ & $19.2 \%$ & $21.2 \%$ \\
\hline $\begin{array}{l}\text { 6-10 (more disadvan- } \\
\text { taged) }\end{array}$ & $1.9 \%$ & $5.1 \%$ & $6.5 \%$ & $14.9 \%$ & $3.1 \%$ & $13.0 \%$ & $19.1 \%$ & $13.1 \%$ \\
\hline
\end{tabular}

${ }^{\mathrm{a}}$ ADI: Area Deprivation Index. 
Table 3. Odds of completing the survey for the different pilot conditions and various sociodemographic factors.

\begin{tabular}{llc}
\hline Variables in multivariate model & OR $^{\mathrm{a}}(95 \% \mathrm{CI})$ & $P$ value \\
\hline Email + letter (vs short email only) & $1.51(0.81-2.82)$ & .20 \\
Email + letter + gift (vs short email only) & $2.29(1.27-4.13)$ & .01 \\
Email + postcard (vs short email only) & $1.02(0.53-1.99)$ & .95 \\
Email + gift card (vs short email only) & $2.03(1.11-3.71)$ & .02 \\
Email + letter + gift card (vs short email only) & $2.83(1.59-5.06)$ & $<.001$ \\
Email + postcard + gift card (vs short email only) & $2.55(1.42-4.58)$ & .002 \\
Previous consent to biobanking study (vs not consented) & $2.15(1.59-2.93)$ & .006 \\
Area Deprivation Index decile (6-10 vs 1-5) & $0.65(0.48-0.88)$ & .01 \\
Cancer status (invasive vs benign/in situ/no cancer) & $1.04(0.71-1.53)$ & .84 \\
Age (per 10 years) & $1.13(0.99-1.29)$ & .08 \\
Non-White (vs White/missing) & $0.68(0.45-1.04)$ & .08 \\
Hispanic (vs non-Hispanic/missing) & $1.11(0.74-1.68)$ & .60 \\
Years since last visit to Moffitt (2-5 vs <2) & $0.52(0.36-0.73)$ & $<.001$ \\
Female (vs male) & $1.33(0.98-1.81)$ & .06 \\
\hline
\end{tabular}

${ }^{\mathrm{a} O R}$ : odds ratio.

Logistic regression analyses were performed to examine the impact of including a prenotification and/or incentive among sociodemographic subgroups. Compared with receiving only an email, response rates were significantly better among those receiving a prenotification letter or postcard (Table 4). A significant increase in response was observed with the prenotification for nearly every sociodemographic group examined, except those last seen at the cancer center more than 2 years ago, those without invasive cancer, and those with a worse socioeconomic disadvantage. The largest increase in response rates was observed for Hispanic and non-White patients. Further, when comparing no incentive to any incentive (gift card or gift), the response rate increased from $5.4 \%$ to $16.7 \%$ overall; every group had significantly improved response rates (Table 5). The largest increases in response rates were for non-White individuals, those with a greater socioeconomic disadvantage (ADI=6-10), and those without an invasive cancer diagnosis (Table 5). The condensed email also had significantly higher response rates; generally, there were no differences in response rates when comparing the two different prenotification modalities (letter vs postcard) or incentive types (gift vs gift card) (see Multimedia Appendix 2). Overall, 192 patients (7\% of 2750) read the consent and answered at least one question but did not complete the survey. The noncompletion rate of the survey was the highest in conditions 1 and $2(10.9 \%$ and $10.8 \%$, respectively) and was the lowest for conditions 6,7 , and 8 $(0.8 \%, 1.2 \%$, and $0.8 \%$, respectively) (data not shown). 
Table 4. Response rates and odds of response when including a pre-email notification letter or postcard overall and by sociodemographic groups.

\begin{tabular}{|c|c|c|c|c|c|}
\hline \multirow[t]{2}{*}{ Socioeconomic group } & \multicolumn{2}{|c|}{ Long or condensed email only $(n=46 / 1250)$} & \multicolumn{2}{|c|}{ Condensed email + letter or postcard $(n=49 / 500)$} & \multirow[t]{2}{*}{$\mathrm{OR}^{\mathrm{a}}(95 \% \mathrm{CI})$} \\
\hline & Complete, n (\%) & Incomplete, n (\%) & Complete, n (\%) & Incomplete, n (\%) & \\
\hline Overall & $46(3.7)$ & $1204(96.3)$ & $49(9.8)$ & $451(90.2)$ & $2.84(1.87-4.31)$ \\
\hline White & $45(4.3)$ & $1000(95.7)$ & $42(10.3)$ & $367(89.7)$ & $2.54(1.64-3.94)$ \\
\hline Non-White & $1(0.5)$ & $204(99.5)$ & $7(7.7)$ & $84(92.3)$ & $17.00(2.06-140.31)$ \\
\hline Non-Hispanic & $42(3.9)$ & $1048(96.2)$ & $42(9.6)$ & $395(90.4)$ & $2.65(1.70-4.13)$ \\
\hline Hispanic & $4(2.5)$ & $156(97.5)$ & $7(11.1)$ & $56(88.9)$ & $4.88(1.37-17.29)$ \\
\hline Male & $18(3.1)$ & 557 (96.9) & $26(10.6)$ & $219(89.4)$ & $3.67(1.97-6.84)$ \\
\hline Female & $28(4.2)$ & $647(95.9)$ & $23(9.0)$ & $232(91.0)$ & $2.29(1.29-4.06)$ \\
\hline$<2$ years since last visit & $37(4.3)$ & $828(95.7)$ & $42(12.5)$ & $293(87.5)$ & $3.21(2.02-5.09)$ \\
\hline $2-5$ years since last visit & $9(2.3)$ & $376(97.7)$ & $7(4.2)$ & $158(95.8)$ & $1.85(0.68-5.06)$ \\
\hline$<65$ years old & $18(3.0)$ & $575(97.0)$ & $19(8.3)$ & $209(91.7)$ & $2.90(1.50-5.64)$ \\
\hline$\geq 65$ years old & $28(4.3)$ & $629(95.7)$ & $30(11.0)$ & $242(89.0)$ & $2.78(1.63-4.76)$ \\
\hline Any cancer & $37(3.9)$ & $902(96.1)$ & $42(11.8)$ & $313(88.2)$ & $3.27(2.06-5.18)$ \\
\hline Benign, in situ, or no cancer & $9(2.9)$ & $302(97.1)$ & $7(4.8)$ & $138(95.2)$ & $1.70(0.62-4.66)$ \\
\hline $\mathrm{ADI}^{\mathrm{b}}$ rank $1-5$ & $30(4.3)$ & $664(95.7)$ & $38(12.9)$ & $256(87.1)$ & $3.29(1.99-5.42)$ \\
\hline ADI rank 6-10 & $13(2.5)$ & $503(97.5)$ & $9(4.7)$ & $181(95.3)$ & $1.92(0.81-4.58)$ \\
\hline
\end{tabular}

${ }^{\mathrm{a}} \mathrm{OR}$ : odds ratio.

${ }^{\mathrm{b}}$ ADI: Area Deprivation Index.

Table 5. Response rates and odds of response when including a pre-email notification of an incentive upon completion overall and by sociodemographic groups.

\begin{tabular}{|c|c|c|c|c|c|}
\hline \multirow[t]{2}{*}{ Socioeconomic group } & \multicolumn{2}{|c|}{ No incentive $(n=95 / 1750)$} & \multicolumn{2}{|c|}{ Any incentive $(n=167 / 1000)$} & \multirow[t]{2}{*}{$\mathrm{OR}^{\mathrm{a}}(95 \% \mathrm{CI})$} \\
\hline & Complete, n (\%) & Incomplete, $\mathrm{n}(\%)$ & Complete, n (\%) & Incomplete, $\mathrm{n}(\%)$ & \\
\hline Overall & $95(5.4)$ & 1655 (94.6) & 167 (16.7) & $833(83.3)$ & $3.49(2.68-4.55)$ \\
\hline White & $87(6.0)$ & $1367(94.0)$ & 144 (17.9) & $659(82.1)$ & $3.43(2.59-4.55)$ \\
\hline Non-White & $8(2.7)$ & $288(97.3)$ & $23(11.7)$ & $174(88.3)$ & $4.76(2.08-10.87)$ \\
\hline Non-Hispanic & $84(5.5)$ & $1443(94.5)$ & $140(16.6)$ & 705 (83.4) & $3.41(2.57-4.54)$ \\
\hline Hispanic & $11(4.9)$ & $212(95.1)$ & $27(17.4)$ & $128(82.6)$ & $4.07(1.95-8.47)$ \\
\hline Male & $44(5.4)$ & $776(94.6)$ & $74(14.3)$ & $445(85.7)$ & $2.93(1.98-4.34)$ \\
\hline Female & $51(5.5)$ & $879(94.5)$ & $93(19.3)$ & $388(80.7)$ & $4.13(2.88-5.93)$ \\
\hline$<2$ years since last visit & $79(6.6)$ & $1121(93.4)$ & $133(19.1)$ & $563(80.9)$ & $3.35(2.49-4.51)$ \\
\hline 2-5 years since last visit & $16(2.9)$ & $534(97.1)$ & $34(11.2)$ & $270(88.8)$ & $4.20(2.28-7.75)$ \\
\hline$<65$ years old & $37(4.5)$ & $784(95.5)$ & $78(16.6)$ & $392(83.4)$ & $4.22(2.80-6.35)$ \\
\hline$\geq 65$ years old & $58(6.2)$ & $871(93.8)$ & $89(16.8)$ & $441(83.2)$ & $3.03(2.14-4.30)$ \\
\hline Any cancer & $79(6.1)$ & $1215(93.9)$ & $133(17.4)$ & $631(82.6)$ & $3.24(2.41-4.35)$ \\
\hline Benign, in situ, or no cancer & $16(3.5)$ & $440(96.5)$ & $34(14.4)$ & $202(85.6)$ & $4.63(2.50-8.58)$ \\
\hline $\mathrm{ADI}^{\mathrm{b}}$ rank $1-5$ & $68(6.9)$ & $920(93.1)$ & $104(18.1)$ & 470 (81.9) & $2.99(2.16-4.14)$ \\
\hline ADI rank 6-10 & $22(3.1)$ & $684(96.9)$ & 57 (14.9) & $325(85.1)$ & $5.45(3.28-9.07)$ \\
\hline
\end{tabular}

${ }^{\mathrm{a}} \mathrm{OR}$ : odds ratio.

${ }^{\mathrm{b}}$ ADI: Area Deprivation Index. 


\section{Discussion}

\section{Overview}

In this study, patients seen at a cancer center who were sent a prenotification letter or postcard had higher response rates to an email invitation for an electronic survey than those not sent a prenotification, with much higher rates among those offered an incentive. Notably, both types of incentives - a small gift included with the prenotification letter or a gift card upon survey completion-improved response rates of electronic surveys for individuals who are often underrepresented in studies, including racial or ethnic minorities and those with low socioeconomic status. Further, prior engagement in biobanking studies and having been seen more recently at the cancer center were strong predictors of higher response rates. Finally, qualitative interviews identified that although the survey itself was not particularly burdensome, cancer patients are experiencing many external stressors due to the pandemic that may interfere with or deter from participation.

\section{Conclusions}

Our study is consistent with previous literature showing that prenotifications can increase response rates, particularly for electronic surveys [4,10,20-22,39]. We also observed higher response rates when including a gift or monetary incentive; however, prior studies only observed an increase with monetary incentives [39-42] and not with other incentives [43-46]. Interestingly, in cancer patients, both a small gift for all invited individuals or a gift card for those who completed the survey led to similar response rates. Above and beyond the cost of sending the letters, postcards, and emails, we spent US \$378 on gifts sent to all 250 invited patients in condition 4 and US $\$ 1280$ on gift cards sent to the 128 participants who completed surveys in conditions 6-8. This yielded a cost of US $\$ 9.69$ per completed survey for those in condition 4 and US $\$ 10$ for those in conditions 6-8. Because these conditions had similar response rates and similar cost per completed survey, each study should evaluate the feasibility and best method for their population.

This study builds on the literature by finding higher response rates in traditionally underrepresented groups when sent a prenotification and/or incentive, which has not been evaluated previously. Additionally, patients with prior involvement in research and who had more recently been seen at the study site were more likely to have a higher response overall, indicating that connection or engagement with the study site in advance of the invitation to research studies could be a critical modality to enhance response rates for remote studies, especially during a pandemic such as COVID-19. The salient nature of this survey may have increased our response rates, although we are unable to evaluate this as participants in all pilot conditions received the same survey.

Ensuring understanding and minimizing burden are important in the development and dissemination of effective surveys for research. Although participants noted that the survey was lengthy, those who completed the survey expressed that they did not feel the survey was overly burdensome. Nevertheless, the length of the survey (approximately 15-20 minutes) may have been a barrier to participation for nonrespondents. Participant suggestions of how to further improve understanding and minimize burden included: (1) reducing the use of medical terminology and incorporating lay terms; (2) adjusting the questions to make the language more specific and less confusing (eg, define what "physical contact" means in the question "How often have you had physical contact with individuals that do not live with you?"); and (3) more clearly communicating the expectations and purpose of the survey through the consent process or via email (eg, length of the survey, expected time commitment). When possible, the length of the survey should be reduced to include questions focused on answering the primary research questions, which may increase response rates [47]. We used adaptive questions such that some questions were only shown if participants self-reported a cancer diagnosis, thereby reducing the overall burden.

\section{Strengths and Limitations}

This study has many strengths, including the use of a mixed methods approach to improve the design of the survey and response rates. As a result of the qualitative interviews, adjustments were made to specific survey questions to improve understanding and the invitation email was substantially condensed to increase readability. We oversampled underrepresented groups to ensure adequate representation, allowing us to evaluate response rates within specific populations. However, due to low response rates with the first pilot condition (long email only), some analyses had limited power. Further, we only conducted qualitative interviews with those who completed the survey and answered the survey question asking whether they would be interested in participating in the interview, which limited our ability to understand why patients did not complete the survey. Our overall response rate was low $(9.5 \%)$, which may be due to our population of older adults and the increased mortality rates among cancer patients, as well as barriers to accessing online surveys. However, 7\% of those invited to participate started the study but did not finish. Future work should attempt to interview nonrespondents to understand the reason for nonparticipation and incomplete participation, which can help to determine strategies to address nonresponse.

\section{Implications}

As the COVID-19 pandemic forces research to evolve, use of electronic surveys is increasing in lieu of in-person interactions [48]. The use of incentives and prenotifications can increase the response rates overall and in vulnerable populations, leading to more diverse studies, increased generalizability, and the ability to assess critical research questions in underrepresented populations. Further, patients engaged in prior research studies appeared to improve response rates, highlighting the importance of the researcher-participant relationship. Our work provides support for use of prenotifications via mail as well as incentives as critical methods to improve electronic survey response rates, particularly in traditionally hard-to-reach populations. 


\section{Acknowledgments}

This research was made possible through the Total Cancer Care Protocol and by the Participant Research, Interventions \& Measurement (PRISM) Core Facility at the H. Lee Moffitt Cancer Center \& Research Institute, an NCI-designated Comprehensive Cancer Center (P30-CA076292). DK was supported by T32-CA090314 (principal investigators: Susan T Vadaparampil and Thomas H Brandon).

\section{Conflicts of Interest}

BDG is an advisory board member for Elly Health, Inc, a former paid consultant for KemPharm, and a paid consultant for SureMed Compliance, none of which is relevant to this manuscript. DER serves on the Board of Directors for NanoString Technologies, Inc., although this position does not relate to her contributions to this paper, and NanoString's business does not relate to the contents of the current manuscript. All other authors have no conflicts of interest to declare.

\section{Multimedia Appendix 1}

Demographic characteristics of pilot groups for respondents and all invited.

[DOCX File, 34 KB-Multimedia Appendix 1]

\section{Multimedia Appendix 2}

Response rates by specific pilot conditions, including a long versus condensed email, comparing prenotification approaches (letter versus postcard) and incentive types (gift to all individuals invited versus US \$10 gift card for survey completion).

[DOCX File, 29 KB-Multimedia Appendix 2]

\section{References}

1. Kongsved SM, Basnov M, Holm-Christensen K, Hjollund NH. Response rate and completeness of questionnaires: a randomized study of Internet versus paper-and-pencil versions. J Med Internet Res 2007 Sep 30;9(3):e25 [FREE Full text] [doi: 10.2196/jmir.9.3.e25] [Medline: 17942387]

2. Meirte J, Hellemans N, Anthonissen M, Denteneer L, Maertens K, Moortgat P, et al. Benefits and disadvantages of electronic patient-reported outcome measures: systematic review. JMIR Perioper Med 2020 Apr 03;3(1):e15588 [FREE Full text] [doi: 10.2196/15588] [Medline: 33393920]

3. Safdar N, Abbo LM, Knobloch MJ, Seo SK. Research methods in healthcare epidemiology: survey and qualitative research. Infect Control Hosp Epidemiol 2016 Nov;37(11):1272-1277 [FREE Full text] [doi: 10.1017/ice.2016.171] [Medline: $\underline{27514583]}$

4. Simsek Z, Veiga J. The electronic survey technique: an integration and assessment. Organ Res Methods 2016 Jun 29;3(1):93-115. [doi: 10.1177/109442810031004]

5. Bliven BD, Kaufman SE, Spertus JA. Electronic collection of health-related quality of life data: validity, time benefits, and patient preference. Qual Life Res 2001;10(1):15-22. [doi: 10.1023/a:1016740312904] [Medline: 11508472]

6. Wintner LM, Giesinger JM, Zabernigg A, Rumpold G, Sztankay M, Oberguggenberger AS, et al. Evaluation of electronic patient-reported outcome assessment with cancer patients in the hospital and at home. BMC Med Inform Decis Mak 2015 Dec 23;15(1):110 [FREE Full text] [doi: 10.1186/s12911-015-0230-y] [Medline: 26699708]

7. Shih T, Fan X. Comparing response rates in e-mail and paper surveys: A meta-analysis. Educ Res Rev 2009 Jan;4(1):26-40. [doi: 10.1016/j.edurev.2008.01.003]

8. Sinclair M, O'Toole J, Malawaraarachchi M, Leder K. Comparison of response rates and cost-effectiveness for a community-based survey: postal, internet and telephone modes with generic or personalised recruitment approaches. BMC Med Res Methodol 2012 Aug 31;12:132 [FREE Full text] [doi: 10.1186/1471-2288-12-132] [Medline: 22938205]

9. Xu M, Richardson L, Campbell S, Pintos J, Siemiatycki J. Response rates in case-control studies of cancer by era of fieldwork and by characteristics of study design. Ann Epidemiol 2018 Jun;28(6):385-391. [doi: 10.1016/j.annepidem.2018.04.001] [Medline: 29703520]

10. Sheehan KB. E-mail survey response rates: a review. J Comput Mediat Commun 2001;6(2). [doi: 10.1111/j.1083-6101.2001.tb00117.x]

11. Czajka J, Beyler A. Declining response rates in federal surveys: trends and implications. Mathematica Policy Research. 2016. URL: https://www.mathematica.org/publications/ declining-response-rates-in-federal-surveys-trends-and-implications-background-paper [accessed 2021-07-29]

12. Tolonen H, Helakorpi S, Talala K, Helasoja V, Martelin T, Prättälä R. 25-year trends and socio-demographic differences in response rates: Finnish adult health behaviour survey. Eur J Epidemiol 2006;21(6):409-415. [doi: 10.1007/s10654-006-9019-8] [Medline: 16804763]

13. de HW. International response trends: results of an international survey. J Off Stat 1999;15(2):129-142. 
14. Bladon T. The downward trend of survey response rates: implications and considerations for evaluators. Can J Program Eval 2009;24(2):131.

15. De Leeuw ED, de Heer W. Trends in household survey nonrespose: a longitudinal and international comparison. In: Groves RM, Dillman DA, Eltinge JL, Little RJA, editors. Survey nonresponse. New York: Wiley; 2002:41-54.

16. Sheldon H, Graham C, Pothecary N, Rasul F. Increasing response rates amongst black and minority ethnic and seldom heard groups. NHS Surveys. Picker Institute; 2007. URL: http://www.nhssurveys.org/Filestore/documents/ Increasing_response_rates_stakeholder_consultation_v6.pdf [accessed 2021-07-29]

17. Graf J, Simoes E, Wißlicen K, Rava L, Walter CB, Hartkopf A, et al. Willingness of patients with breast cancer in the adjuvant and metastatic setting to use electronic surveys (ePRO) depends on sociodemographic factors, health-related quality of life, disease status and computer skills. Geburtshilfe Frauenheilkd 2016 May;76(5):535-541 [FREE Full text] [doi: 10.1055/s-0042-105872] [Medline: 27239062]

18. Padala PR, Jendro AM, Padala KP. Conducting clinical research during the COVID-19 pandemic: investigator and participant perspectives. JMIR Public Health Surveill 2020 Apr 06;6(2):e18887 [FREE Full text] [doi: 10.2196/18887] [Medline: $\underline{32250281]}$

19. Mourad M, Bousleiman S, Wapner R, Gyamfi-Bannerman C. Conducting research during the COVID-19 pandemic. Semin Perinatol 2020 Nov;44(7):151287 [FREE Full text] [doi: 10.1016/j.semperi.2020.151287] [Medline: 32807490]

20. McCluskey S, Topping AE. Increasing response rates to lifestyle surveys: a pragmatic evidence review. Perspect Public Health 2011 Mar;131(2):89-94. [doi: 10.1177/1757913910389423] [Medline: 21462753]

21. McPeake J, Bateson M, O'Neill A. Electronic surveys: how to maximise success. Nurse Res 2014 Jan;21(3):24-26. [doi: 10.7748/nr2014.01.21.3.24.e1205] [Medline: 24460562]

22. Edwards PJ, Roberts I, Clarke MJ, Diguiseppi C, Wentz R, Kwan I, et al. Methods to increase response to postal and electronic questionnaires. Cochrane Database Syst Rev 2009 Jul 08(3):MR000008. [doi: 10.1002/14651858.MR000008.pub4] [Medline: 19588449]

23. Phillips AW, Reddy S, Durning SJ. Improving response rates and evaluating nonresponse bias in surveys: AMEE Guide No. 102. Med Teach 2016;38(3):217-228. [doi: 10.3109/0142159X.2015.1105945] [Medline: 26648511]

24. Kind AJH, Buckingham WR. Making neighborhood-disadvantage metrics accessible - The Neighborhood Atlas. N Engl J Med 2018 Jun 28;378(26):2456-2458 [FREE Full text] [doi: 10.1056/NEJMp1802313] [Medline: 29949490]

25. Neighborhood Atlas. Area Deprivation Index v3. Department of Medicine University of Wisconsin School of Medicine and Public Health. 2018. URL: https://www.neighborhoodatlas.medicine.wisc.edu/ [accessed 2020-12-16]

26. Sørensen K, Van den Broucke S, Fullam J, Doyle G, Pelikan J, Slonska Z, (HLS-EU) Consortium Health Literacy Project European. Health literacy and public health: a systematic review and integration of definitions and models. BMC Public Health 2012 Jan 25;12(1):80 [FREE Full text] [doi: 10.1186/1471-2458-12-80] [Medline: 22276600]

27. Yan T, Fricker S, Tsai S. Response burden: what is it and what predicts it? In: Beatty P, Collins D, Kaye L, Padilla JL, Willis G, Wilmot A, editors. Advances in Questionnaire Design, Development, Evaluation and Testing. Hoboken, NJ: John Wiley \& Sons; 2020:193-212.

28. Lingler J, Schmidt K, Gentry A, Hu L, Terhorst L. A new measure of research participant burden: brief report. J Empir Res Hum Res Ethics 2014 Oct;9(4):46-49 [FREE Full text] [doi: 10.1177/1556264614545037] [Medline: 26125079]

29. Archibald M, Ambagtsheer R, Casey M, Lawless M. Using Zoom videoconferencing for qualitative data collection: perceptions and experiences of researchers and participants. Int J Qual Methods 2019 Sep 11;18:160940691987459. [doi: $10.1177 / 1609406919874596]$

30. Gray L, Wong-Wylie G, Rempel G, Cook K. Expanding qualitative research interviewing strategies: Zoom video communications. Qual Rep 2020 May 15;25(5):1292-1301. [doi: 10.46743/2160-3715/2020.4212]

31. Vindrola-Padros C, Vindrola-Padros B. Quick and dirty? A systematic review of the use of rapid ethnographies in healthcare organisation and delivery. BMJ Qual Saf 2018 Apr;27(4):321-330. [doi: 10.1136/bmjqs-2017-007226] [Medline: 29263139]

32. Vindrola-Padros C, Johnson G. Rapid techniques in qualitative research: a critical review of the literature. Qual Health Res 2020 Aug;30(10):1596-1604. [doi: 10.1177/1049732320921835] [Medline: 32667277]

33. Boeije H. A purposeful approach to the constant comparative method in the analysis of qualitative interviews. Qual Quant 2002;36(4):391-409. [doi: 10.4135/9781849209403.n920]

34. Lewis-Beck M, Bryman A, Liao T. The Sage encyclopedia of social science research methods. Newbury Park, CA: Sage Publications; 2003.

35. Namey E, Guest G, McKenna K, Chen M. Evaluating bang for the buck: a cost-effectiveness comparison between individual interviews and focus groups based on thematic saturation levels. Am J Eval 2016 Jul 09;37(3):425-440. [doi: $10.1177 / 1098214016630406$ ]

36. Guest G. Sampling and selecting participants in field research. In: Bernard HR, Gravlee CC, editors. Handbook of methods in cultural anthropology. Second edition. Lanham, MD: Rowman \& Littlefield; 2014:215-249.

37. Harris PA, Taylor R, Thielke R, Payne J, Gonzalez N, Conde JG. Research electronic data capture (REDCap)--a metadata-driven methodology and workflow process for providing translational research informatics support. J Biomed Inform 2009 Apr;42(2):377-381 [FREE Full text] [doi: 10.1016/j.jbi.2008.08.010] [Medline: 18929686] 
38. Harris PA, Taylor R, Minor BL, Elliott V, Fernandez M, O'Neal L, REDCap Consortium. The REDCap consortium: Building an international community of software platform partners. J Biomed Inform 2019 Jul;95:103208 [FREE Full text] [doi: 10.1016/j.jbi.2019.103208] [Medline: $\underline{31078660]}$

39. Jia P, Furuya-Kanamori L, Qin Z, Jia P, Xu C. Association between response rates and monetary incentives in sample study: a systematic review and meta-analysis. Postgrad Med J 2021 Aug;97(1150):501-510. [doi: 10.1136/postgradmedj-2020-137868] [Medline: 32848082]

40. Yu S, Alper HE, Nguyen A, Brackbill RM, Turner L, Walker DJ, et al. The effectiveness of a monetary incentive offer on survey response rates and response completeness in a longitudinal study. BMC Med Res Methodol 2017 Apr 26;17(1):77 [FREE Full text] [doi: $\underline{10.1186 / \mathrm{s} 12874-017-0353-1]}$ [Medline: 28446131]

41. Agarwal A, Raad D, Kairouz V, Fudyma J, Curtis AB, Schünemann HJ, et al. The effect of a monetary incentive for administrative assistants on the survey response rate: a randomized controlled trial. BMC Med Res Methodol 2016 Aug 05;16:94 [FREE Full text] [doi: 10.1186/s12874-016-0201-8] [Medline: 27495186]

42. Cheung YTD, Weng X, Wang MP, Ho SY, Kwong ACS, Lai VWY, et al. Effect of prepaid and promised financial incentive on follow-up survey response in cigarette smokers: a randomized controlled trial. BMC Med Res Methodol 2019 Jul 04;19(1):138 [FREE Full text] [doi: 10.1186/s12874-019-0786-9] [Medline: 31272393]

43. Pieper D, Kotte N, Ober P. The effect of a voucher incentive on a survey response rate in the clinical setting: a quasi-randomized controlled trial. BMC Med Res Methodol 2018 Aug 16;18(1):86 [FREE Full text] [doi: 10.1186/s12874-018-0544-4] [Medline: 30115037]

44. Cook DA, Wittich CM, Daniels WL, West CP, Harris AM, Beebe TJ. Incentive and reminder strategies to improve response rate for internet-based physician surveys: a randomized experiment. J Med Internet Res 2016 Sep 16;18(9):e244 [FREE Full text] [doi: 10.2196/jmir.6318] [Medline: 27637296]

45. Bakan J, Chen B, Medeiros-Nancarrow C, Hu JC, Kantoff PW, Recklitis CJ. Effects of a gift certificate incentive and specialized delivery on prostate cancer survivors' response rate to a mailed survey: a randomized-controlled trial. J Geriatr Oncol 2014 Apr;5(2):127-132. [doi: 10.1016/j.jgo.2013.11.005] [Medline: 24495697]

46. Warwick H, Hutyra C, Politzer C, Francis A, Risoli T, Green C, et al. Small social incentives did not improve the survey response rate of patients who underwent orthopaedic surgery: a randomized trial. Clin Orthop Relat Res 2019 Jul;477(7):1648-1656 [FREE Full text] [doi: 10.1097/CORR.0000000000000732] [Medline: 31135552]

47. Rolstad S, Adler J, Rydén A. Response burden and questionnaire length: is shorter better? A review and meta-analysis. Value Health 2011 Dec;14(8):1101-1108 [FREE Full text] [doi: 10.1016/j.jval.2011.06.003] [Medline: 22152180]

48. Hlatshwako TG, Shah SJ, Kosana P, Adebayo E, Hendriks J, Larsson EC, et al. Online health survey research during COVID-19. Lancet Digit Health 2021 Feb;3(2):e76-e77 [FREE Full text] [doi: 10.1016/S2589-7500(21)00002-9] [Medline: 33509387]

\section{Abbreviations}

ADI: area deprivation index

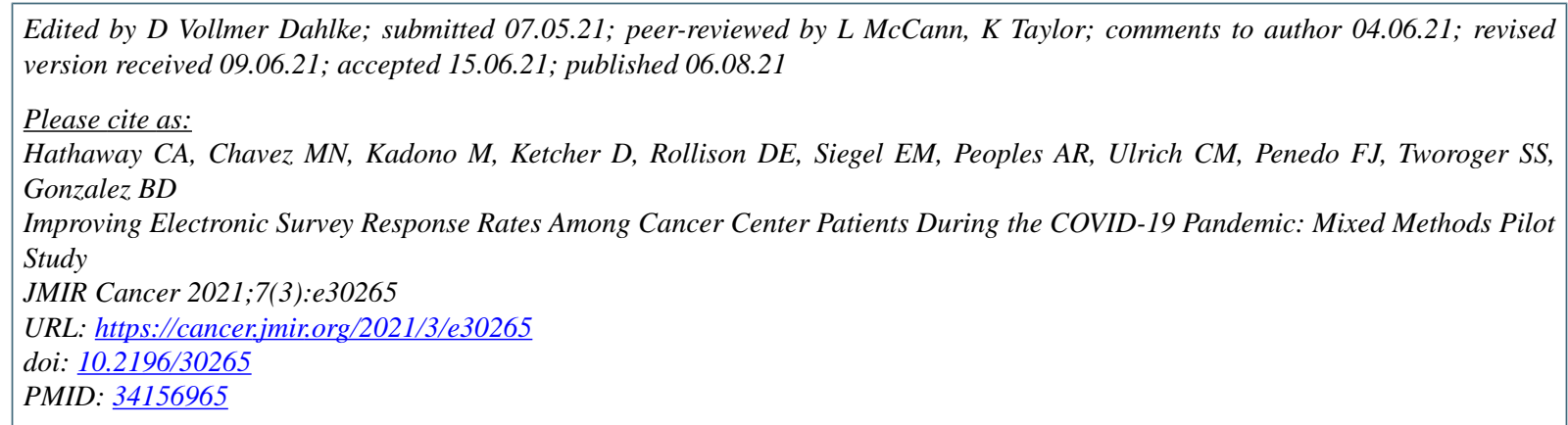

CCassandra A Hathaway, Melody N Chavez, Mika Kadono, Dana Ketcher, Dana E Rollison, Erin M Siegel, Anita R Peoples, Cornelia M Ulrich, Frank J Penedo, Shelley S Tworoger, Brian D Gonzalez. Originally published in JMIR Cancer (https://cancer.jmir.org), 06.08.2021. This is an open-access article distributed under the terms of the Creative Commons Attribution License (https://creativecommons.org/licenses/by/4.0/), which permits unrestricted use, distribution, and reproduction in any medium, provided the original work, first published in JMIR Cancer, is properly cited. The complete bibliographic information, a link to the original publication on https://cancer.jmir.org/, as well as this copyright and license information must be included. 